\title{
The Association Between Neighborhood Social Vulnerability and COVID-19 Testing, Positivity, and Incidence in Alabama and Louisiana
}

\author{
Gabriela R. Oates ${ }^{1} \mathbb{D} \cdot$ Lucia D. Juarez $^{1} \cdot$ Ronald Horswell $^{2} \cdot$ San $\mathrm{Chu}^{2} \cdot$ Lucio Miele $^{3} \cdot$ Mona N. Fouad $^{1}$. \\ William A. Curry ${ }^{1} \cdot$ Daniel Fort $^{4} \cdot$ William B. Hillegass $^{5} \cdot$ Denise M. Danos $^{3}$
}

Accepted: 29 April 2021 / Published online: 9 May 2021

(c) The Author(s), under exclusive licence to Springer Science+Business Media, LLC, part of Springer Nature 2021

\begin{abstract}
Racial/ethnic and socioeconomic disparities in COVID-19 burden have been widely reported. Using data from the state health departments of Alabama and Louisiana aggregated to residential Census tracts, we assessed the relationship between social vulnerability and COVID-19 testing rates, test positivity, and incidence. Data were cumulative for the period of February 27, 2020 to October 7, 2020. We estimated the association of the 2018 Social Vulnerability Index (SVI) overall score and theme scores with COVID-19 tests, test positivity, and cases using multivariable negative binomial regressions. We adjusted for rurality with 2010 Rural-Urban Commuting Area codes. Regional effects were modeled as fixed effects of counties/parishes and state health department regions. The analytical sample included 1160 Alabama and 1105 Louisiana Census tracts. In both states, overall social vulnerability and vulnerability themes were significantly associated with increased COVID-19 case rates (RR 1.57, 95\% CI 1.45-1.70 for Alabama; RR 1.36, 95\% CI 1.26-1.46 for Louisiana). There was increased COVID-19 testing with higher overall vulnerability in Louisiana (RR 1.26, 95\% CI 1.14-1.38), but not in Alabama (RR 0.95, 95\% CI 0.89-1.02). Consequently, test positivity in Alabama was significantly associated with social vulnerability (RR $1.66,95 \%$ CI 1.57-1.75), whereas no such relationship was observed in Louisiana (RR 1.05, 95\% CI 0.98-1.12). Social vulnerability is a risk factor for COVID-19 infection, particularly among racial/ethnic minorities and those in disadvantaged housing conditions without transportation. Increased testing targeted to vulnerable communities may contribute to reduction in test positivity and overall COVID-19 disparities.
\end{abstract}

Keywords COVID-19 testing $\cdot$ COVID-19 incidence $\cdot$ Neighborhood $\cdot$ Social vulnerability $\cdot$ Racial/ethnic disparities

Gabriela R. Oates

goates@uab.edu

1 School of Medicine, University of Alabama At Birmingham, Birmingham, AL, USA

2 Pennington Biomedical Research Center, Baton Rouge, LA, USA

3 Health Sciences Center, Louisiana State University, New Orleans, LA, USA

4 Ochsner Center for Outcomes Research, Ochsner Health, New Orleans, LA, USA

5 University of Mississippi Medical Center, Jackson, MS, USA

\section{Introduction}

Stark racial and socioeconomic disparities in rates of COVID-19 cases have emerged across the U.S. since the beginning of the pandemic. For example, the proportion of African Americans affected by the virus is at least twice the proportion of African Americans in the overall population [1-6]; similar disparities have been reported among Hispanics/Latinx [7, 8]. When interpreting reports of racial/ethnic differences in COVID-19 incidence or outcomes, it is important to recognize that race and ethnicity are social constructs without a genetic basis [9-11]. As such, observed association of race/ethnicity with COVID-19 cases are largely attributable to unequal social conditions, including higher service-sector employment, residential crowding, substandard housing, and poverty in communities of color. Ecological analyses of population-based COVID-19 case rates show 
greater case burden in areas with lower socioeconomic status and greater population density [12-14]. In addition, spatial analyses have identified that greater case rates are associated with area-level measures of education, household size, and crowding [15].

Similar patterns of disparities have been observed in COVID-19 test positivity. Studies show greater test positivity for racial/ethnic minorities and those of lower socioeconomic status in large healthcare system cohorts, including veterans and children [16-18]. Results from early in the pandemic also showed that higher test positivity was associated with area-level social and environmental exposures, such as residence in neighborhoods with higher financial, housing, and transportation insecurity and worse air quality [16]. Ecological associations between COVID-19 test positivity and income, race, and number of dependent children have also been reported [19]. Therefore, it is imperative to analyze COVID-19 data along multiple dimensions of inequality to clarify how racial/ethnic, socioeconomic, environmental, and spatial factors are intertwined in their contributions for observed disparities in COVID-19 burden. Such approach will also help inform more effective strategies for mitigating the disproportionate impact of this and future pandemics on vulnerable populations.

One tool developed by the Centers for Disease Control and Prevention (CDC) to assist local, state, and federal government in deploying resources during disease outbreaks and other disasters is the Social Vulnerability Index (SVI). Constructed from 15 variables in the American Community Survey grouped into four themes (socioeconomic status, household composition and disability, minority status and language, and housing and transportation), the SVI assigns national and state percentile rankings to each Census tract, with higher values indicating greater vulnerability.

Several recent studies have reported associations between SVI scores and COVID-19 case rates [20-22]. In addition, an earlier analysis indicated that the socioeconomic status and minority status themes had the strongest correlation with case rates [23]. However, all these analyses have been conducted at the county level, which limits specificity to smaller geographic areas within counties. One study used SVI on a Census tract level to determine relationships with COVID19 incidence in Louisiana, but did not assess COVID-19 testing or test positivity rates or explore regional effects [24]. It is important to understand how social vulnerability at the neighborhood level affects patterns of testing, positivity, and cases in order to develop impactful public health strategies for disease prevention and mitigation.

In the current study, we used data from the state health departments of Alabama and Louisiana aggregated to residential Census tracts, proxies for neighborhoods, to determine the association between neighborhood social vulnerability (SVI) and COVID-19 testing, positivity, and diagnosis-based incidence. We also assessed which SVI themes drive the relationship between social vulnerability and COVID-19 testing, positivity, and cases in the two states.

\section{Methods}

Data on COVID-19 tests and cases, aggregated to residential Census tracts, were obtained from the Alabama Department of Public Health and the Louisiana Department of Health for the period of February 27, 2020 to October 7, 2020. Data were cumulative for the entire study period.

\section{Measures}

The outcome variables, measured on a Census tract level, were number of COVID-19 tests and number of COVID-19 cases based on PCR-positive lab-confirmed tests reported to the either state. COVID-19 cumulative incidence of tests and cases per 1000 persons was calculated by dividing the total number of confirmed COVID-19 tests or cases in the Census tract by the total population of the Census tract in 2018 and multiplying by 1000 . Test positivity rate was calculated as the total number of cases over the total number of tests during the study period.

The 2018 Social Vulnerability Index (SVI) was the main predictor variable. The SVI is constructed from 15 variables in the 2014-2018 American Community Survey aggregated to Census tracts and grouped into four themes: socioeconomic status; household composition and disability; minority status and language; and housing and transportation. Variables are ranked across U.S. Census tracts, and a percentile rank is calculated for each Census tract. The resulting index ranges from 0 to 1 , with higher values indicating higher vulnerability. The full methodologic details of the creation of the SVI are available elsewhere [25].

We examined associations of each outcome with the percentile ranking of the overall SVI score as well as with the percentile ranking of each SVI theme score in order to understand which aspects of social vulnerability are most relevant to COVID-19 incidence. We used the U.S. Census population estimates for each Census tract provided in the CDC 2018 SVI database. Tracts with zero estimates for total population or with population less than 1000 were removed from the analysis.

As population density and level of urbanization may affect the relationship between social vulnerability and incidence of COVID-19, we adjusted for these confounders with the U.S. Department of Agriculture 2010 Rural-Urban Commuting Area (RUCA) codes, which classify U.S. Census tracts on the basis of population density, urbanization, and daily commuting. We used the primary RUCA codes 
(whole numbers 1-10), which delineate metropolitan, micropolitan, small town, and rural commuting areas based on the size and direction of the primary (largest) commuting flows [26]. Potential regional effects on the level of counties and state health department regions were explored as well.

\section{Statistical Analysis}

Descriptive statistics and results from analyses are presented for each state separately. We show mean, standard deviation, and range for the 15 Census variables in the SVI, grouped into four themes. We estimated the association between the overall SVI score, SVI theme scores, and COVID-19 cumulative incidence of tests, positivity, and cases using multivariable negative binomial regressions with estimation of the dispersion parameters using the restricted pseudo-likelihood method [27]. The generalized linear regression models for cumulative incidence of tests and cases used the natural log of the total population divided by 1000 for each Census tract as an offset variable to predict reported COVID-19 tests or cases per 1000 persons. For positivity rate models, the offset variable was the natural $\log$ of tests for each Census tract. To assess the degree to which the association between social vulnerability and COVID-19 tests, positivity, and cases may be due to regional variation, we additionally compared models adjusted for fixed effects of counties/parishes and state health department regions with models without regional effects. Analyses were done in SAS version 9.4 (SAS Institute, Cary NC).

\section{Results}

Between February 27 and October 7, 2020, 972850 diagnostic tests for COVID-19 were administered in Alabama and 2245327 in Louisiana. On a state level, the testing rate in Louisiana was nearly 2.5 times that of Alabama (483.2 vs 200.5 tests per 1000 population). The state of Louisiana had higher COVID-19 case rate (32.3 vs 28.2 per 1000 population) but half the test positivity rate of Alabama (6.7\% vs $14.1 \%)$. The distributions of COVID-19 test, case, and positivity rates in the two states are presented in Fig. 1.

The analytical sample included 1160 Alabama Census tracts and 1105 Louisiana Census tracts (17 Alabama and 12 Louisiana Census tracts were removed due to having population of less than 1000 residents or missing information for the SVI). Descriptive statistics per Census tract of the sample are presented in Table 1. The mean cumulative incidence of confirmed COVID-19 cases per Census tract was $29.5 \pm 14.4$ (range 4.4-165.7) per 1000 persons in Alabama, and $32.8 \pm 13.5$ (range $0-173.3$ ) per 1000 persons in Louisiana. Census tracts in Louisiana had higher population density than those in Alabama $(2560 \pm 3136$ vs $994 \pm 1250$ per square mile). Poverty, unemployment, income, and education characteristics were similar, but Louisiana tracts had higher proportion of racial/ethnic minorities, households without a vehicle, and residential crowding, while Alabama tracts had higher proportion of people age $\geq 65$ and population with a disability (Table 1).

Figure 2 shows risk ratios (RRs) of COVID-19 test rates, test positivity, and case rates by overall SVI score and four individual SVI theme scores. In both states, overall social vulnerability and each vulnerability theme were associated with increased COVID-19 case rates (overall RR 1.57, 95\% CI 1.45-1.70 for Alabama; overall RR 1.36, 95\% CI 1.26-1.46 for Louisiana). However, the relationship of social vulnerability with testing rates and test positivity differed in the two states. In Alabama, overall vulnerability was not associated with COVID-19 testing rates, whereas in Louisiana, there was increased testing with higher overall vulnerability (RR 1.26, 95\% CI 1.14-1.38), lower socioeconomic status (RR 1.10, 95\% CI 1.00-1.22), minority status (RR $1.17,95 \%$ CI 1.06-1.30), and disadvantaged housing/transportation (RR 1.58, 95\% CI 1.43-1.74). Consequently, test positivity in Alabama was associated with each aspect of social vulnerability (overall RR 1.66, 95\% CI 1.57-1.75),
(A) Test rate by state

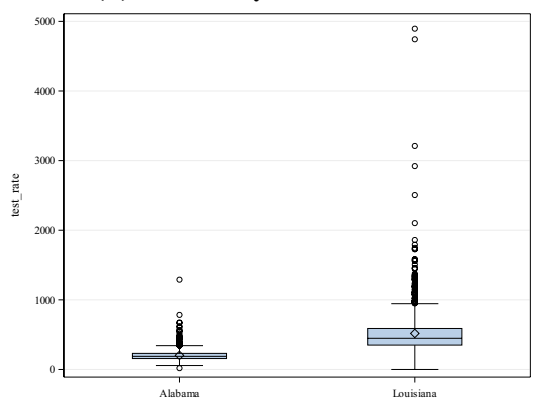

(B) Test positivity by state

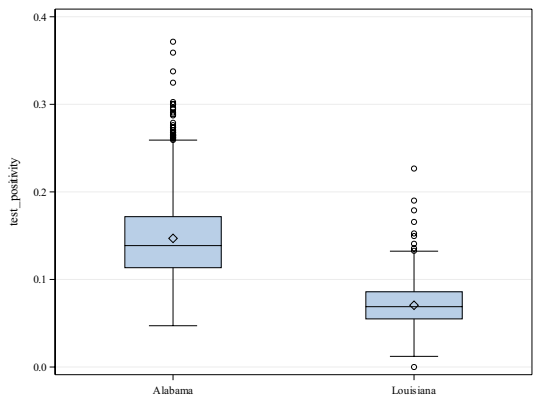

(C) Case rate by state

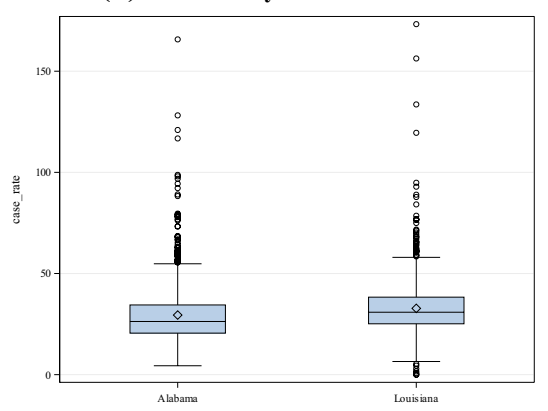

Fig. 1 COVID-19 cumulative diagnostic test rates, test positivity rates, and cumulative case rates in Alabama and Louisiana (February 27 October 7, 2020): a Test rate by state; b Test positivity by state; c Case rate by state 
Table 1 Descriptive statistics of Alabama $(\mathrm{N}=1160)$ and Louisiana $(\mathrm{N}=1105)$ Census tracts, for the period of February 27 to October 7, 2020

\begin{tabular}{|c|c|c|c|c|c|}
\hline \multirow[t]{2}{*}{ Variable } & & \multicolumn{2}{|c|}{ Alabama $(\mathrm{N}=1160)$} & \multicolumn{2}{|c|}{ Louisiana $(\mathrm{N}=1105)$} \\
\hline & & Mean (SD) & Range & Mean (SD) & Range \\
\hline \multicolumn{2}{|c|}{ Census tract COVID-19 tests per 1000 persons } & $202.8(79.7)$ & $18.8-1290.0$ & $517.7(335.4)$ & $0-4895.1$ \\
\hline \multicolumn{2}{|c|}{ Census tract COVID-19 cases per 1000 persons } & $29.5(14.4)$ & $4-165.7$ & $32.8(13.5)$ & $0-173.3$ \\
\hline \multicolumn{2}{|l|}{ Census tract total population } & $4183(2227)$ & 1026-19892 & $4205(2301)$ & $1014-18524$ \\
\hline \multicolumn{2}{|c|}{ Census tract population density (residents/sq mi) } & $994(1250)$ & $4-8724$ & $2560(3136)$ & $3-18400$ \\
\hline \multirow[t]{4}{*}{ Theme 1: Socioeconomic } & $\%$ Below poverty line & $20.0(12.4)$ & $1-84.3$ & $21.4(12.8)$ & $0-72.0$ \\
\hline & Unemployment rate & $7.7(5.3)$ & $0-41.7$ & $7.6(4.9)$ & $0-27.2$ \\
\hline & Per capita income & $25450(10260)$ & $3568-83438$ & $26643(12280)$ & $6651-97982$ \\
\hline & $\%$ No high school diploma & $15.6(8.3)$ & $0-59.5$ & $16.0(8.8)$ & $0-46.6$ \\
\hline \multirow[t]{4}{*}{ Theme 2: Household Composition } & $\%$ Persons aged 65 and older & $16.7(5.3)$ & $0-39.7$ & $15.1(5.2)$ & $0-41.7$ \\
\hline & $\%$ Persons aged 17 and younger & $22.2(5.5)$ & $0-45.9$ & $22.9(6.2)$ & $1-45.3$ \\
\hline & $\%$ With a disability & $17.3(6.0)$ & $0-38.8$ & $15.5(5.2)$ & $0-36.2$ \\
\hline & $\%$ Single-parent households & $9.7(6.2)$ & $0-40.0$ & $11.1(6.4)$ & $0-41.2$ \\
\hline \multirow[t]{2}{*}{ Theme 3: Minority \& Language } & $\begin{array}{l}\% \text { Minority (all except non-Hispanic } \\
\text { Whites) }\end{array}$ & $38.8(29.1)$ & $1-100.0$ & $45.1(28.9)$ & $1-100.0$ \\
\hline & $\begin{array}{l}\% \text { Persons who speak English less } \\
\text { than well }\end{array}$ & $1.0(2.0)$ & $0-16.5$ & $1.5(2.6)$ & $0-23.2$ \\
\hline \multirow{5}{*}{$\begin{array}{l}\text { Theme 4: Housing and Transporta- } \\
\text { tion }\end{array}$} & $\%$ Multi-unit housing & $6.3(12.1)$ & $0-84.6$ & $7.0(12.6)$ & $0-91.0$ \\
\hline & $\%$ Mobile homes & $13.7(14.0)$ & $0-58.5$ & $11.8(13.6)$ & $0-81.9$ \\
\hline & $\begin{array}{l}\% \text { Housing units with more people } \\
\text { than rooms }\end{array}$ & $1.8(2.0)$ & $0-13.8$ & $2.4(2.3)$ & $0-15.0$ \\
\hline & $\begin{array}{l}\% \text { Households with no vehicle avail- } \\
\text { able }\end{array}$ & $7.4(7.0)$ & $0-53.1$ & $10.1(9.7)$ & $0-64.2$ \\
\hline & $\begin{array}{l}\% \text { Persons in institutionalized group } \\
\text { quarters }\end{array}$ & $2.5(8.3)$ & $0-94.5$ & $2.9(8.7)$ & $0-96.9$ \\
\hline
\end{tabular}

Fig. 2 Risk ratios of COVID-19 test rates, test positivity, and case rates by Social Vulnerability Index (SVI) overall score and individual SVI theme scores for Alabama and Louisiana Census tracts
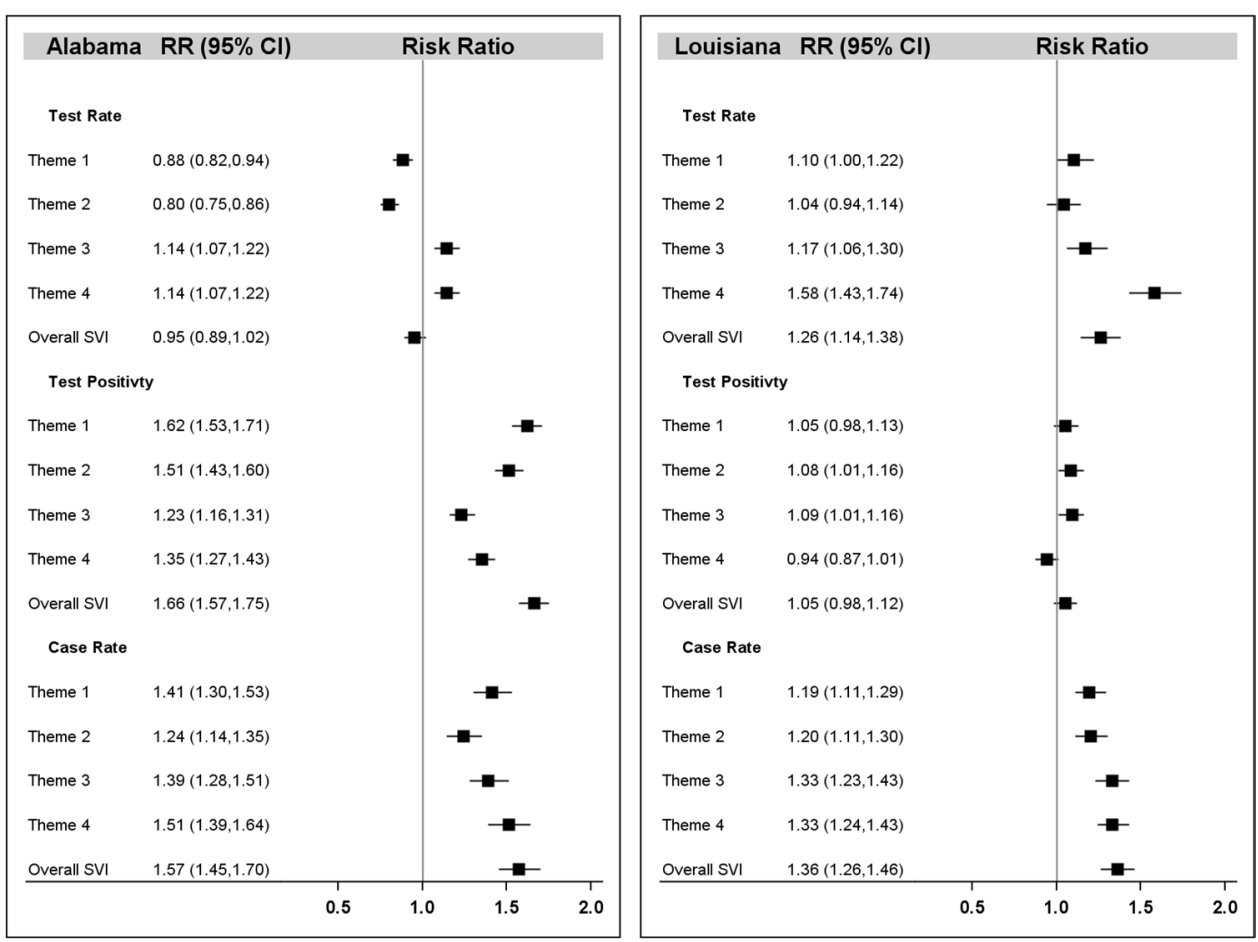
while such relationship was not observed in Louisiana (overall RR $1.05,95 \%$ CI $0.98-1.12$ ).

Table 2 and Table 3 show the relative risk of COVID19 test rates, test positivity, and case rates by SVI themes, comparing single-theme models to multivariable models that include all SVI themes. In multivariable SVI theme models, in both states, COVID-19 test rates decreased with socioeconomic vulnerability (RR $0.83,95 \%$ CI $0.76-0.91$ for Alabama; RR 0.82, 95\% CI 0.72-0.95 for Louisiana). Conversely, in both states, COVID-19 test rates increased with minority status (RR 1.15, 95\% CI 1.07-1.23 for Alabama; RR 1.13, 95\% CI 1.01-1.26 for Louisiana) and housing/transportation vulnerability (RR 1.27, 95\% CI 1.18-1.37 for Alabama; RR 1.73, 95\% CI 1.55-1.93 for Louisiana). In multivariable SVI theme models, in both states, test positivity increased with vulnerable household composition (RR 1.24, 95\% CI 1.16-1.33 for Alabama; RR 1.10 95\% CI 1.01-1.19 for Louisiana) and racial/ethnic minority status (RR 1.09, 95\% CI 1.03-1.15 for Alabama; RR $1.1095 \%$ CI 1.02-1.19 for Louisiana). However, in Alabama, test positivity also increased with low socioeconomic status (RR 1.36, 95\% CI 1.26-1.46), whereas in Louisiana, test positivity decreased with housing/transportation vulnerability (RR $0.87,95 \%$ CI $0.80-0.95)$. In multivariable SVI theme models, case rates increased with low socioeconomic status in Alabama (RR 1.12, 95\% CI 1.00,1.25) but decreased with low socioeconomic status in Louisiana (RR 0.87, 95\% CI $0.79,0.97)$. In both states, the SVI themes with strongest independent effects for case rates included minority status (RR 1.23, 95\% CI 1.13-1.34 for Alabama; RR 1.30, 95\% CI 1.20-1.41 for Louisiana) and housing/transportation (RR 1.32, 95\% CI 1.20-1.46 for Alabama; RR 1.28, 95\% CI $1.18-1.40$ for Louisiana).

Figure 3 shows a graphic comparison of all SVI theme analyses in both states, by levels of adjustment (rurality, state health department regions, and counties/parishes). After conditioning on rurality and other themes, the association between COVID-19 testing and minority status was no longer significant (RR 1.06, 95\% CI 0.99-1.14 for Alabama; RR 1.06, 95\% CI 0.95-1.19 for Louisiana), indicating that the relationship was at least partially driven by higher rates of testing and greater densities of minority residents in metropolitan areas.

Table 2 COVID-19 test rates, test positivity, and case rates: individual and multivariable models of Social Vulnerability Index themes for Alabama Census tracts $(\mathrm{N}=1160)$

\begin{tabular}{|c|c|c|c|c|c|c|}
\hline & \multicolumn{2}{|c|}{ COVID-19 test rates } & \multicolumn{2}{|c|}{ COVID-19 test positivity } & \multicolumn{2}{|c|}{ COVID-19 case rates } \\
\hline & Individual themes & $\begin{array}{l}\text { Multivariable } \\
\text { model }^{\mathrm{a}}\end{array}$ & Individual themes & $\begin{array}{l}\text { Multivariable } \\
\text { model }^{\mathrm{a}}\end{array}$ & Individual themes & $\begin{array}{l}\text { Multivariable } \\
\text { model }^{1 \mathrm{a}}\end{array}$ \\
\hline & $\mathrm{RR}(95 \% \mathrm{CI})$ & & RR $(95 \% \mathrm{CI})$ & & RR $(95 \% \mathrm{CI})$ & \\
\hline $\begin{array}{l}\text { Theme 1: Socio- } \\
\text { economic status } \\
\text { (income, poverty, } \\
\text { unemploy- } \\
\text { ment, }<\text { high- } \\
\text { school education) }\end{array}$ & $0.88(0.82,0.94)$ & $0.83(0.76,0.91)$ & $1.62(1.53,1.71)$ & $1.36(1.26,1.46)$ & $1.41(1.30,1.53)$ & $1.12(1.00,1.25)$ \\
\hline $\begin{array}{l}\text { Theme } 2 \text { : House- } \\
\text { hold composi- } \\
\text { tion (age } \geq 65, \\
\text { age } \leq 17, \text { disabil- } \\
\text { ity, single-parent } \\
\text { households) }\end{array}$ & $0.80(0.76,0.86)$ & $0.82(0.76,0.89)$ & $1.51(1.43,1.60)$ & $1.24(1.16,1.33)$ & $1.24(1.14,1.35)$ & $1.05(0.95,1.16)$ \\
\hline $\begin{array}{l}\text { Theme 3: Minority } \\
\text { status \& language } \\
\text { (race, limited } \\
\text { English language } \\
\text { proficiency) }\end{array}$ & $1.14(1.07,1.22)$ & $1.15(1.07,1.23)$ & $1.23(1.16,1.31)$ & $1.09(1.03,1.15)$ & $1.39(1.28,1.51)$ & $1.23(1.13,1.34)$ \\
\hline $\begin{array}{l}\text { Theme 4: Hous- } \\
\text { ing/transporta- } \\
\text { tion (crowding, } \\
\text { multiunit housing, } \\
\text { mobile homes, } \\
\text { group quarters, no } \\
\text { vehicle access) }\end{array}$ & $1.14(1.07,1.22)$ & $1.27(1.18,1.37)$ & $1.35(1.27,1.43)$ & $1.06(0.99,1.13)$ & $1.51(1.39,1.64)$ & $1.32(1.20,1.46)$ \\
\hline
\end{tabular}

${ }^{\text {a }}$ Adjusted for all SVI theme scores

Bold face indicates statistical significance at alpha $=0.05$ 
Table 3 COVID-19 test rates, test positivity, and case rates: individual and multivariable models of Social Vulnerability Index themes for Louisiana Census tracts $(\mathrm{N}=1105)$

\begin{tabular}{|c|c|c|c|c|c|c|}
\hline & \multicolumn{2}{|c|}{ COVID-19 test rates } & \multicolumn{2}{|c|}{ COVID-19 test positivity } & \multicolumn{2}{|c|}{ COVID-19 case rates } \\
\hline & Individual themes & $\begin{array}{l}\text { Multivariable } \\
\text { model }^{\mathrm{a}}\end{array}$ & Individual themes & $\begin{array}{l}\text { Multivariable } \\
\text { model }^{\mathrm{a}}\end{array}$ & Individual themes & $\begin{array}{l}\text { Multivariable } \\
\text { model }^{\mathrm{a}}\end{array}$ \\
\hline & $\mathrm{RR}(95 \% \mathrm{CI})$ & & $\mathrm{RR}(95 \% \mathrm{CI})$ & & $\mathrm{RR}(95 \% \mathrm{CI})$ & \\
\hline $\begin{array}{l}\text { Theme 1: Socio- } \\
\text { economic status } \\
\text { (income, poverty, } \\
\text { unemploy- } \\
\text { ment, < high- } \\
\text { school education) }\end{array}$ & $1.10(1.00,1.22)$ & $0.82(0.72,0.95)$ & $1.05(0.98,1.13)$ & $1.04(0.94,1.15)$ & $1.19(1.11,1.29)$ & $0.87(0.79,0.97)$ \\
\hline $\begin{array}{l}\text { Theme } 2 \text { : House- } \\
\text { hold composi- } \\
\text { tion (age } \geq 65 \text {, } \\
\text { age } \leq 17 \text {, disabil- } \\
\text { ity, single-parent } \\
\text { households) }\end{array}$ & $1.04(0.94,1.14)$ & $0.95(0.85,1.07)$ & $1.08(1.01,1.16)$ & $1.10(1.01,1.19)$ & $1.20(1.11,1.30)$ & $1.17(1.07,1.28)$ \\
\hline $\begin{array}{l}\text { Theme 3: Minority } \\
\text { status \& language } \\
\text { (race, limited } \\
\text { English language } \\
\text { proficiency) }\end{array}$ & $1.17(1.06,1.30)$ & $1.13(1.01,1.26)$ & $1.09(1.01,1.16)$ & $1.10(1.02,1.19)$ & $1.33(1.23,1.43)$ & $1.30(1.20,1.41)$ \\
\hline $\begin{array}{l}\text { Theme 4: Hous- } \\
\text { ing/transporta- } \\
\text { tion (crowding, } \\
\text { multiunit housing, } \\
\text { mobile homes, } \\
\text { group quarters, no } \\
\text { vehicle access) }\end{array}$ & $1.58(1.43,1.74)$ & $1.73(1.55,1.93)$ & $0.94(0.87,1.01)$ & $0.87(0.80,0.95)$ & $1.33(1.24,1.43)$ & $1.28(1.18,1.40)$ \\
\hline
\end{tabular}

${ }^{a}$ Adjusted for all SVI theme scores

Bold face indicates statistical significance at alpha $=0.05$

Further adjustment for regional effects (county/parish or state health department region) did indicate some regional variation in COVID-19 testing patterns and positivity. In Alabama, the average within-county disparity in test positivity for socioeconomic status (RR 1.21, 95\% CI 1.13-1.28) and housing composition (RR 1.13, 95\% CI 1.07-1.20) vulnerabilities were less than the overall state estimates. In Louisiana, the average within-parish disparity in test positivity for socioeconomic status (RR 1.20, 95\% CI 1.10-1.30) and minority status (RR 1.22, 95\% CI 1.14-1.30) vulnerabilities were greater than overall state estimates.

\section{Discussion}

We analyzed cumulative data from the state health departments of Alabama and Louisiana aggregated to residential Census tracts to determine the association between social vulnerability and COVID-19 test rates, test positivity, and case rates from the beginning of the pandemic through October 7, 2020.
In both states, results show a positive and significant association between all measures of social vulnerability and COVID-19 incidence. Based on overall SVI score, those residing in vulnerable Alabama and Louisiana tracts had up to $57 \%$ and $36 \%$ higher risk of COVID-19 diagnosis, respectively. When assessing individual SVI themes, our results confirmed that neighborhoods with greater proportion of racial/ethnic minorities and those with housing conditions that promote close contact had the greatest risk for COVID19 infection. In interpreting these findings, we should note that a plausible biological mechanism directly linking race/ ethnicity to poor COVID-19 outcomes has not been demonstrated. What makes race important is its close association with socioeconomic position and class circumstances, which are also associated with risk-escalating comorbidities. Understanding COVID-19 disparities requires integration of racial stratification with class because the effects of race cannot be assessed without considering the effects of class [28]. This argument is supported by qualitative studies of COVID19 , which report that most barriers to testing among racial/ ethnic minorities were related to adverse socioeconomic conditions, such as lack of transportation, housing, utilities, 

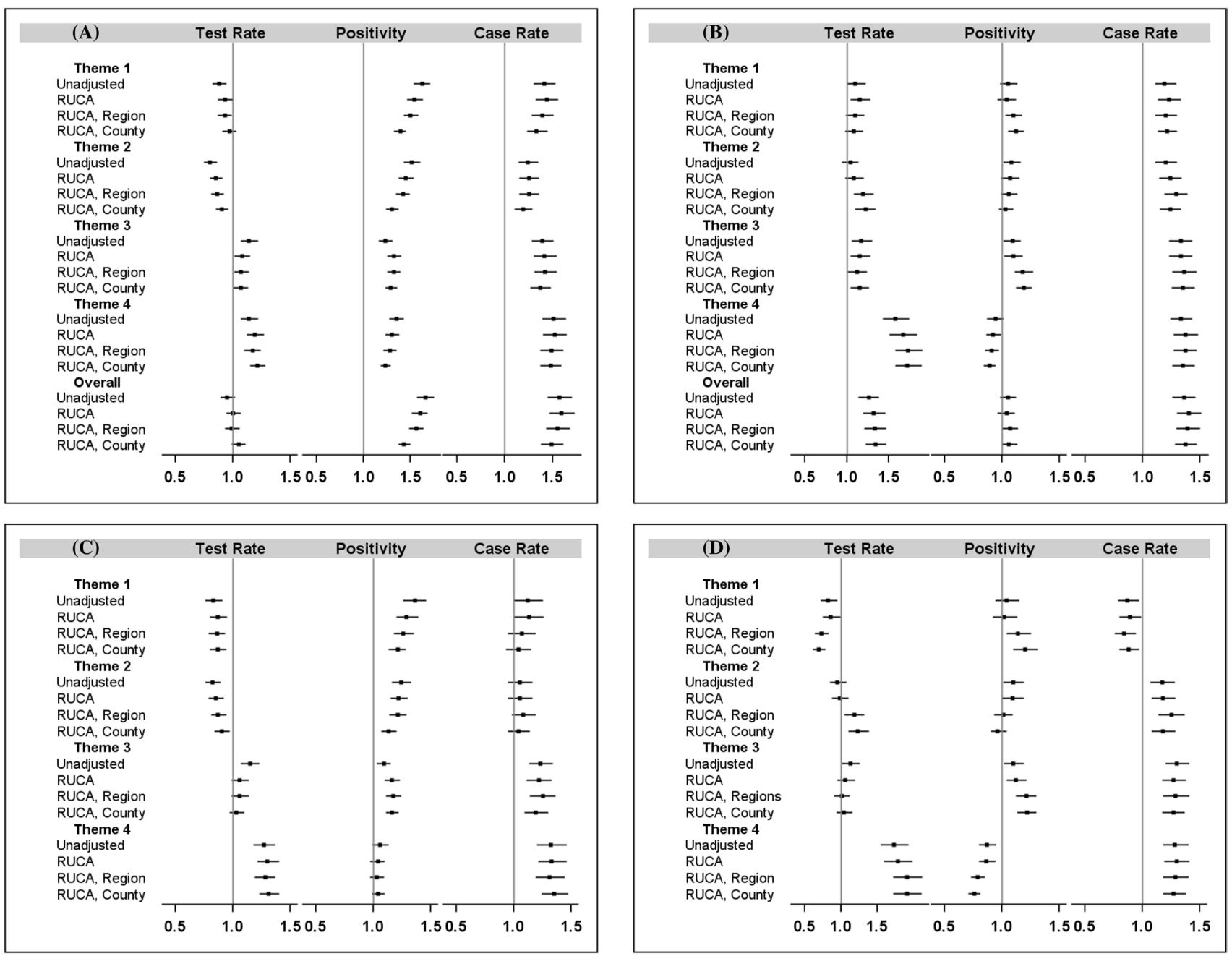

Fig. 3 Conditional estimates of risk ratios and 95\% confidence intervals for COVID-19 tests, positivity, and cases in a Alabama single-theme models, b Louisiana single-theme models, c Alabama multiple-theme models, and d Louisiana multiple-theme models

and food insecurity $[1,29,30]$. Those still employed faced additional stress from working with the public in low-wage service jobs with little social distancing, no health insurance, or childcare [30].

Our findings highlight major differences in COVID19 testing between two otherwise similar Southern states. Although Alabama and Louisiana are nearly identical in land mass area and similar in both population size ( 4.9 vs 4.7 million) and demographics (69\% vs 64\% White non-Hispanic), Alabama had considerably lower test rates and twice the test positivity of Louisiana. Additionally, the association of social vulnerability with testing rates differed between the two states. On average, Louisiana had greater distribution of tests to vulnerable populations and little to no disparities in test positivity. In contrast, overall, Alabama did not test vulnerable populations at higher rates, and vulnerable neighborhoods had up to 57\% higher risk of positive COVID-19 test than non-vulnerable tracts. These differences could be indicative of different COVID-19 testing strategies between the two states, both in terms of quantity and distribution. The differences may also be due to unmeasured confounders that differentiate Alabama's population from the population of Louisiana, such as health beliefs and COVID-19 testing attitudes.

Adequate testing is paramount for public health response in the control of communicable diseases. Accurate identification of cases is required in order for successful mitigation strategies such as contact tracing and quarantines to be potentially effective. In the absence of a testing shortage, test positivity is a key indicator of population disease control and community spread. Therefore, $\mathrm{CDC}$ recommendations for schools, childcare, bars, restaurants, and public venues operational strategies are based on test positivity rates. Several studies have used comprehensive population-based COVID-19 testing data to identify areas with low testing rates and high test-positivity rates as hot spots in need of 
increased testing capacity [3, 31, 32]. Our findings suggest that targeted testing in vulnerable communities may reduce disparities in COVID-19 incidence, and thus reduce morbidity and mortality overall. This conclusion is supported by a study of COVID-19 cases early in the pandemic, which reported that overall SVI measured on a county level is associated with increased rates of COVID-19, except in states with high testing rates [21].

This ecological study has several limitations. The reported effects are population estimates rather than individual-level vulnerability. In addition, we do not assess change over time, although availability, eligibility, and rates of testing were not constant during the study period. Further, the reported associations represent average relationship across each state during the study period and do not preclude regional variation in the observed relationships. While sensitivity analyses showed some regional variation in COVID-19 testing and positivity, we conclude that the overall study results are not confounded by regional differences in population composition and COVID-19 outcomes within either state. Future studies should investigate spatial-temporal trends in testing and outcomes and the potential for targeted testing to mediate the spread of disease in longitudinal analyses. Finally, there are a number of unmeasured factors, such as availability of tests, differences in health beliefs or attitudes toward COVID-19 testing, or differences in disease-mitigating public health policy, such as timing and duration of shelter-inplace orders that may account for the observed associations in the current study. However, E-value assessments suggest the observed significant associations between overall SVI measure and positive COVID case rates (RR 1.57, 95\% CI 1.45-1.70 for Alabama; RR 1.36, 95\% CI 1.26-1.46 for Louisiana) are likely to be robust to unmeasured and unknown confounders. The E-values for the SVI and positive COVID rate associations for Alabama and Louisiana are 2.06 and 2.53 for the point estimates and 1.83 and 2.26 for the confidence intervals, respectively [33]. The E-values indicate that unknown and unmeasured confounders must have relative risk associations of approximately 2.0 to 2.5 with both the SVI measure and COVID positivity rates to explain the observed associations. E-values of this magnitude generally indicate reasonable robustness of the observed associations to unknown and unmeasured confounding [34].

\section{Conclusion}

Social vulnerability is a risk factor for COVID-19 infection, particularly among racial/ethnic minorities and those in disadvantaged housing conditions without transportation. Increased testing targeted to vulnerable communities may contribute to reduction in test positivity as well as overall COVID-19 disparities and facilitate disease control.
Authors' Contributions All authors have made substantial contributions to (1) the conception and design of the study, the acquisition of data, analysis and interpretation of data, (2) the drafting of the article and revising it critically for important intellectual content, (3) final approval of the version of the manuscript to be submitted.

Funding Supported in part by U54MD000502 from the National Institute on Minority Health and Health Disparities, U54GM104940 from the National Institute of General Medical Sciences, and U54GM115428 from the National Institute of General Medical Sciences. The content is solely the responsibility of the authors and does not necessarily represent the official views of the National Institutes of Health.

Data Availability Data for Louisiana are publicly available from the Louisiana Department of Health. Data for Alabama are available under Data Use Agreement with the Alabama Department of Public Health.

Code availability SAS code is available upon request.

\section{Declarations}

Conflict of interest The authors do not have conflicts of interest or competing interests.

Ethical approval The study was approved by the Institutional Review Board of the University of Alabama at Birmingham (protocol 300005492) and the Institutional Review Board of the Louisiana State University Health Sciences Center (protocol 1280).

\section{References}

1. Millett, G. A., Jones, A. T., Benkeser, D., Baral, S., Mercer, L., Beyrer, C., \& Sullivan, P. S. (2020). Assessing differential impacts of COVID-19 on black communities. Annals of Epidemiology, 47, 37-44. https://doi.org/10.1016/j.annepidem.2020.05.003

2. Yancy, C. W. (2020). COVID-19 and African Americans. JAMA, 323(19), 1891-1892. https://doi.org/10.1001/jama.2020.6548

3. Lieberman-Cribbin, W., Tuminello, S., Flores, R. M., \& Taioli, E. (2020). Disparities in COVID-19 Testing and Positivity in New York City. American Journal of Preventive Medicine, 59(3), 326332. https://doi.org/10.1016/j.amepre.2020.06.005

4. Thakur, N., Lovinsky-Desir, S., Bime, C., Wisnivesky, J. P., \& Celedon, J. C. (2020). The Structural and social determinants of the racial/ethnic disparities in the US COVID-19 pandemic what's our role? American Journal of Respiratory and Critical Care Medicine, 202(7), 943-949. https://doi.org/10.1164/rccm. 202005-1523PP

5. Turner-Musa, J., Ajayi, O., \& Kemp, L. (2020). Examining social determinants of health, stigma, and COVID-19 disparities. Healthcare (Basel), 8(2), 168. https://doi.org/10.3390/healthcare 8020168

6. Khalatbari-Soltani, S., Cumming, R. C., Delpierre, C., \& KellyIrving, M. (2020). Importance of collecting data on socioeconomic determinants from the early stage of the COVID-19 outbreak onwards. Journal of Epidemiology and Community Health, 74(8), 620-623. https://doi.org/10.1136/jech-2020-214297

7. Rodriguez-Diaz, C. E., Guilamo-Ramos, V., Mena, L., Hall, E., Honermann, B., Crowley, J. S., \& Millett, G. A. (2020). Risk for COVID-19 infection and death among Latinos in the United States: examining heterogeneity in transmission dynamics. Annals 
of Epidemiology, 52(46-53), e42. https://doi.org/10.1016/j.annep idem.2020.07.007

8. Macias Gil, R., Marcelin, J. R., Zuniga-Blanco, B., Marquez, C., Mathew, T., \& Piggott, D. A. (2020). COVID-19 pandemic: disparate health impact on the hispanic/latinx population in the United States. Journal of Infectious Diseases, 222(10), 1592-1595. https://doi.org/10.1093/infdis/jiaa474

9. Caldwell, S. H., \& Popenoe, R. (1995). Perceptions and misperceptions of skin color. Annals of Internal Medicine, 122(8), 614617. https://doi.org/10.7326/0003-4819-122-8-199504150-00010

10. Kahn, J. (2004). How a drug becomes "ethnic": law, commerce, and the production of racial categories in medicine. Yale J Health Policy Law Ethics, 4(1): 1-46. Retrieved from https://www.ncbi. nlm.nih.gov/pubmed/15052858

11. Hoover, E. L. (2007). There is no scientific rationale for racebased research. Journal of the National Medical Association, 99(6): 690-692. Retrieved from https://www.ncbi.nlm.nih.gov/ pubmed/17595942

12. Abedi, V., Olulana, O., Avula, V., Chaudhary, D., Khan, A., Shahjouei, S., \& Zand, R. (2020). Racial, economic, and health inequality and COVID-19 infection in the United States. Journal of Racial and Ethnic Health Disparities. https://doi.org/10.1007/ s40615-020-00833-4

13. Lewis, N. M., Friedrichs, M., Wagstaff, S., Sage, K., LaCross, N., Bui, D., \& Dunn, A. (2020). Disparities in COVID-19 incidence, hospitalizations, and testing, by area-level deprivation - Utah, March 3-July 9, 2020. MMWR. Morbidity and Mortality Weekly Report, 69(38), 1369-1373. https://doi.org/10.15585/mmwr. $\mathrm{mm} 6938 \mathrm{a} 4$

14. Zhang, C. H., \& Schwartz, G. G. (2020). Spatial disparities in coronavirus incidence and mortality in the united states: an ecological analysis as of May 2020. Journal of Rural Health, 36(3), 433-445. https://doi.org/10.1111/jrh.12476

15. Maroko, A. R., Nash, D., \& Pavilonis, B. T. (2020). COVID-19 and inequity: a comparative spatial analysis of New York City and Chicago hot spots. Journal of Urban Health, 97(4), 461-470. https://doi.org/10.1007/s11524-020-00468-0

16. Rozenfeld, Y., Beam, J., Maier, H., Haggerson, W., Boudreau, K., Carlson, J., \& Medows, R. (2020). A model of disparities: risk factors associated with COVID-19 infection. Int J Equity Health, 19(1), 126. https://doi.org/10.1186/s12939-020-01242-z

17. Rentsch, C. T., Kidwai-Khan, F., Tate, J. P., Park, L. S., King, J. T., Jr., Skanderson, M., \& Justice, A. C. (2020). Covid-19 by race and ethnicity: a national cohort study of 6 million United States Veterans. medRxiv. https://doi.org/10.1101/2020.05.12.20099135

18. Goyal, M. K., Simpson, J. N., Boyle, M. D., Badolato, G. M., Delaney, M., McCarter, R., \& Cora-Bramble, D. (2020). Racial and/or Ethnic and Socioeconomic Disparities of SARS-CoV-2 Infection Among Children. Pediatrics, 146(4), e2020009951. https://doi.org/10.1542/peds.2020-009951

19. Whittle, R. S., \& Diaz-Artiles, A. (2020). An ecological study of socioeconomic predictors in detection of COVID-19 cases across neighborhoods in New York City. BMC Medicine, 18(1), 271. https://doi.org/10.1186/s12916-020-01731-6

20. Dasgupta, S., Bowen, V. B., Leidner, A., Fletcher, K., Musial, T., Rose, C., \& Oster, A. M. (2020). Association between social vulnerability and a county's risk for becoming a COVID-19 hotspot - United States, June 1-July 25, 2020. MMWR. Morbidity and Mortality Weekly Report, 69(42), 1535-1541. https://doi.org/10. 15585/mmwr.mm6942a3

21. Karaye, I. M., \& Horney, J. A. (2020). The impact of social vulnerability on COVID-19 in the U.S. an analysis of spatially varying relationships. American Journal of Preventive Medicine, 59(3), 317-325. https://doi.org/10.1016/j.amepre.2020.06.006
22. Neelon, B., Mutiso, F., Mueller, N. T., Pearce, J. L., \& BenjaminNeelon, S. E. (2021). Spatial and temporal trends in social vulnerability and COVID-19 incidence and death rates in the United States. PLoS ONE, 16(3), e0248702. https://doi.org/10.1371/journ al.pone. 0248702

23. Nayak, A., Islam, S. J., Mehta, A., Ko, Y. A., Patel, S. A., Goyal, A., \& Quyyumi, A. A. (2020). Impact of social vulnerability on COVID-19 incidence and outcomes in the United States. medRxiv. https://doi.org/10.1101/2020.04.10.20060962

24. Biggs, E. N., Maloney, P. M., Rung, A. L., Peters, E. S., \& Robinson, W. T. (2020). The relationship between social vulnerability and COVID-19 incidence among louisiana census tracts. Frontiers in Public Health, 8, 617976. https://doi.org/10.3389/fpubh.2020. 617976

25. CDC's Social Vulnerability Index (SVI) data and documentation download. (2020). Washington, DC: ATSDR Retrieved from https://svi.cdc.gov/data-and-tools-download.html

26. Rural-Urban Commuting Area Codes. (2020). Retrieved from https://www.ers.usda.gov/data-products/rural-urban-commu ting-area-codes/. from United States Department of Agriculture, Economic Research Service https://www.ers.usda.gov/data-produ cts/rural-urban-commuting-area-codes/

27. Wolfinger, R., \& O'Connell, M. (1993). Generalized linear mixed models: a pseudo-likelihood approach. Journal of Statistical Computation and Simulation, 48(3-4), 233-243. https://doi.org/10. 1080/00949659308811554

28. Williams, D. R. (1999). Race, socioeconomic status, and health. The added effects of racism and discrimination. Ann N Y Acad Sci, 896, 173-188. Retrieved from http://www.ncbi.nlm.nih.gov/ pubmed/10681897

29. Marmot, M. (2015). The health gap: the challenge of an unequal world. The Lancet, 386(10011), 2442-2444. https://doi.org/10. 1016/S0140-6736(15)00150-6

30. Bateman, L. B., Schoenberger, Y. M., Hansen, B., Osborne, T. N., Okoro, G. C., Speights, K. M., \& Fouad, M. N. (2021). Confronting COVID-19 in under-resourced, African American neighborhoods: a qualitative study examining community member and stakeholders' perceptions. Ethnicity and Health, 26(1), 49-67. https://doi.org/10.1080/13557858.2021.1873250

31. Cordes, J., \& Castro, M. C. (2020). Spatial analysis of COVID-19 clusters and contextual factors in New York City. Spat Spatiotemporal Epidemiol, 34, 100355. https://doi.org/10.1016/j.sste.2020. 100355

32. Dryden-Peterson, S., Velasquez, G. E., Stopka, T. J., Davey, S., Lockman, S., \& Ojikutu, B. O. (2021). Disparities in SARSCoV-2 testing in massachusetts during the COVID-19 pandemic. JAMA Network Open, 4(2), e2037067. https://doi.org/10.1001/ jamanetworkopen.2020.37067

33. Mathur, M. B., Ding, P., Riddell, C. A., \& VanderWeele, T. J. (2018). Web Site and R package for computing E-values. Epidemiology, 29(5), e45-e47. https://doi.org/10.1097/EDE.00000 00000000864

34. VanderWeele, T. J., \& Ding, P. (2017). Sensitivity Analysis in Observational Research: Introducing the E-Value. Annals of Internal Medicine, 167(4), 268-274. https://doi.org/10.7326/M16-2607

Publisher's Note Springer Nature remains neutral with regard to jurisdictional claims in published maps and institutional affiliations. 